\title{
Influence of light presence and biomass concentration on nutrient kinetic removal from urban wastewater by Scenedesmus obliquus
}

\author{
J. Ruiz ${ }^{a, *}$, Z. Arbib a,b , P.D. Álvarez-Díaz a , C. Garrido-Pérez ${ }^{a}$, J. Barragán a,c, J.A. Perales ${ }^{a}$ \\ a Department of Environmental Technology, Centro Andaluz de Ciencia y Tecnología Marinas (CACYTMAR), Campus de Excelencia Internacional del Mar \\ (CEI.MAR), University of Cádiz, Campus Universitario de Puerto Real, 11510 Puerto Real, Cádiz, Spain \\ ${ }^{\mathrm{b}}$ Aqualia Gestión Integral del Agua S.A., Avenida camino de Santiago, 40, 28050 Madrid, Spain \\ c Chiclana Natural, S.A. Pza. de España, S.N. 11130 Chiclana de la Frontera, Cádiz, Spain
}

\section{A R T I C L E I N F O}

\section{Article history:}

Received 14 October 2013

Received in revised form 27 January 2014

Accepted 3 March 2014

Available online 11 March 2014

\section{Keywords:}

Urban wastewater

Nutrient removal

Light-Dark

Biomass concentration

Microalgae

\begin{abstract}
A B S T R A C T
This work was aimed at studying the effect of light-darkness and high-low biomass concentrations in the feasibility of removing nitrogen and phosphorus from urban treated wastewater by the microalga Scenedesmus obliquus. Laboratory experiments were conducted in batch, where microalgae were cultured under different initial biomass concentrations (150 and $1500 \mathrm{mg} \mathrm{SS}^{-1}$ ) and light conditions (dark or illuminated). Nutrient uptake was more dependent on internal nutrient content of the biomass than on light presence or biomass concentration. When a maximum nitrogen or phosphorus content in the biomass was reached (around $8 \%$ and 2\%, respectively), the removal of that nutrient was almost stopped. Biomass concentration affected more than light presence on the nutrient removal rate, increasing significantly with its increase. Light was only required to remove nutrients when the maximum nutrient storage capacity of the cells was reached and further growth was therefore needed. Residence times to maintain a stable biomass concentration, avoiding the washout of the reactor, were much higher than those needed to remove the nutrients from the wastewater. This ability to remove nutrients in the absence of light could lead to new configurations of reactors aimed to wastewater treatment.
\end{abstract}

(c) 2014 Elsevier B.V. All rights reserved.

\section{Introduction}

High concentrations of nitrogen and phosphorus compounds must be removed from wastewaters as they can potentially lead to eutrophication in receiving waters, causing toxicity to aquatic life and oxygen depletion. Those pollutants can be removed by a variety of biological and physicochemical processes, but the unit processes commonly used are costly and produce a high amount of sludge. Besides, most common biological nitrogen and phosphorus removal processes from wastewater are complex, being a proper operation crucial to achieve a full nutrient removal potential (Jeyanayagami, 2005).

From $60 \%$ to $80 \%$ of energy consumption during wastewater treatment is associated with nutrient removal (Maurer et al., 2003), being those processes enormously energy intensive. A shift away is required from energy intensive consuming processes towards low energy requiring processes or even energy producing processes.

\footnotetext{
* Corresponding author. Tel.: +34 956016587; fax: +34 956016746

E-mail address: jesus.ruizgonzalez@uca.es (J. Ruiz).
}

The cultivation of algae in wastewater offers the combined advantages of removing the excess nutrients and simultaneously producing algal biomass (Arbib et al., 2013; Franchino et al., 2013; Ruiz et al., 2011). In the field of study of microalgae, it has been demonstrated that through that process not only nutrients can be efficiently removed from wastewater, but also energetic balance may be positive by producing biofuel or direct combustion of algal biomass (Sturm and Lamer, 2011).

Nutrient removal by microalgae is influenced by many factors, such as light, temperature or nutrient concentration (Richmond, 2004). While some works have been conducted to study nitrogen and phosphorus uptake kinetics by microalgae (Flynn and Fasham, 1997; Flynn et al., 1997; Lavoie and de la Noüe, 1985; Portielje and Lijklema, 1994; Powell et al., 2008, 2009; Ruiz et al., 2013a,b; Tam and Wong, 1989), none of them was aimed to determine the influence of different biomass concentrations and the effect of presence/absence of light on nitrogen and phosphorus uptake rate. Those parameters have a great relevance on the process since a higher biomass concentration can lead to a greater contribution in nutrient removal due to nutrients adsorbed to the surface of the cells (Boyd and Musig, 1981; Martínez Sancho et al., 1999). Regarding the light, the possibility of operating a reactor 
Table 1

Nutrient composition of wastewater used in this study.

\begin{tabular}{|c|c|c|c|c|c|c|c|}
\hline $\mathrm{TN}\left(\mathrm{mg} \mathrm{N}^{-1}\right)$ & $\mathrm{NH}_{4}^{+}\left(\mathrm{mg} \mathrm{Nl}^{-1}\right)$ & $\mathrm{NO}_{3}{ }^{-}\left(\mathrm{mg} \mathrm{Nl}^{-1}\right)$ & $\mathrm{NO}_{2}^{-}\left(\mathrm{mg} \mathrm{Nl}^{-1}\right)$ & $\mathrm{N}_{\text {organic }}\left(\mathrm{mg} \mathrm{Nl}^{-1}\right)$ & $\mathrm{TP}\left(\mathrm{mg} \mathrm{Pl}^{-1}\right)$ & $\begin{array}{l}\mathrm{PO}_{4}^{3-} \\
\left(\mathrm{mg} \mathrm{Pl}^{-1}\right)\end{array}$ & $\mathrm{P}_{\text {organic }}\left(\mathrm{mg} \mathrm{Pl}^{-1}\right)$ \\
\hline $17.45 \pm 0.78$ & $16.08 \pm 0.80$ & $0.27 \pm 0.05$ & $0.14 \pm 0.02$ & 0.96 & $2.60 \pm 0.002$ & $2.15 \pm 0.008$ & 0.45 \\
\hline
\end{tabular}

of microalgae specifically aimed to nutrient removal in darkness could entail a significant reduction in the investment costs of the process.

In this work, microalgae have been cultured in batch in reactors under different conditions in order to study how light, darkness and biomass concentration affect to the nitrogen and phosphorus consumption from wastewater. Different species of the genus Scenedesmus have previously been grown successfully in different wastewaters (Hodaifa et al., 2012; McGinn et al., 2012; Park et al., 2010), indicating that those organisms are appropriate candidates for this kind of studies.

\section{Materials and methods}

\subsection{Microalgae strain}

The green microalga Scenedesmus obliquus (SAG 276-10) was obtained from Sammlung von Algenkulturen, Pflanzenphysiologisches Institut (Universität Göttingen, Germany). The inoculum was cultured in synthetic culture medium Combo two-fold (Kilham et al., 1998) and maintained in exponential growth at a temperature of $20 \pm 1^{\circ} \mathrm{C}$, a light intensity of $250 \mu \mathrm{mol} \mathrm{m}^{-2} \mathrm{~s}^{-1}$ and a $14: 10 \mathrm{~h}$ light:dark cycle.

Microalgae were centrifuged before inoculation to concentrate them and obtaining different biomass concentrations in the reactors. Centrifugation was done at $4200 \mathrm{rpm}$ for $3 \mathrm{~min}$ (Centrifuge Mixtasel-BL Selecta $\left.{ }^{\circledR}\right)$, obtaining a clear supernatant. Those centrifugation conditions had been previously tested to verify $S$. obliquus was not considerably harmed and could successfully grow afterwards. Two inocula, one of centrifuged biomass and another one of non-centrifuged biomass, grew simultaneously under the same culture conditions, presenting the centrifuged biomass a productivity of only a $7 \%$ lower.

\subsection{Wastewater}

Secondary effluent from a conventional urban wastewater treatment plant (WWTP) located in Arcos de la Frontera in Cádiz $\left(36^{\circ} 44^{\prime} 56.56^{\prime \prime} \mathrm{N}, 5^{\circ} 47^{\prime} 37.12^{\prime \prime} \mathrm{O}\right.$ - Spain) was used as culture medium. Wastewater was filtered through a fiber filter of $1 \mu \mathrm{m}$ pore diameter (PALL Corporation, Type A/E) to remove suspended solids, not being submitted to any further sterilization process.

Typical nitrogen and phosphorus contents of treated urban wastewaters of low strength are $15.2 \mathrm{mg} \mathrm{TNl}^{-1}$ and $2.6 \mathrm{mg} \mathrm{TPl}^{-1}$ (calculated according to Metcalf and Eddy (1991)). Total nitrogen content (Table 1) of wastewater used in this study was similar to the mentioned effluent, however total phosphorus concentration was lower $\left(0.93 \mathrm{mg} \mathrm{TPl}^{-1}\right)$. In order to simulate a typical treated wastewater and to observe a noticeable decrease in the phosphorus content from the wastewater, soluble phosphorus was increased in laboratory. Wastewater was enriched in $\mathrm{K}_{2} \mathrm{HPO}_{4}$ to reach $2.6 \mathrm{mg} \mathrm{TPl}^{-1}$. Table 1 shows the wastewater characterization after phosphate addition.

\subsection{Experimental set-up}

Microalgae were grown at $20 \pm 1{ }^{\circ} \mathrm{C}$ and borosilicate Pyrex bottles $(12.5 \mathrm{~cm}$ diameter $\times 14.5 \mathrm{~cm}$ height $)$ were used as photobioreactors, with 21 of culture volume. The bottles were sealed with caps with three lines: one for the introduction of air, one for air outlet, and the last one for sampling. The system was aerated from the bottom with atmospheric filtered air $(0.2 \mu \mathrm{m})$ at an airflow of $1.251 \mathrm{~min}^{-1}$ (0.63 vvm).

Four reactors in different culture conditions were installed in an incubator chamber with control of temperature. Two of them were irradiated at $250 \mu \mathrm{mol} \mathrm{m}^{-2} \mathrm{~s}^{-1}$ with a photoperiod of $14: 10 \mathrm{~h}$ light/dark and the other two were maintained in darkness during the whole experiment. The illumination was provided by eight fluorescent lamps (4 PHILIPS Master TLD 58 W/840 Cool White and 4 SYLVANIA Grolux F58 W/GRO-T8 Daylight) placed horizontally at one side of the photobioreactor. One illuminated reactor and one reactor in darkness were inoculated with S. obliquus at a concentration of $150 \mathrm{mgSSl}^{-1}$, and the other reactors (one illuminated and one in darkness) were inoculated with $1500 \mathrm{mg} \mathrm{SSl}^{-1}$ (Table 2).

\subsection{Analytical methods}

Biomass concentration was measured gravimetrically as dry weight according to the standardized method 2540-D (APHA, 1992).

Samples for nutrient analysis were taken from the reactor and filtered through a fiber filter of $0.45 \mu \mathrm{m}$ pore diameter (PALL Corporation, Type A/E) to separate biomass. Phosphates (4500-PE), ammonia (4500- $\left.\mathrm{NH}_{3} \mathrm{D}\right)$ and nitrite $\left(4500 \mathrm{NO}_{2}{ }^{-} \mathrm{B}\right)$ were measured colorimetrically according to standard methods (APHA, 1992). Nitrate determinations were performed according to Spectroquant ${ }^{\circledR}$ colorimetric test kit (Cod. 1.14773.0001, Merck). Total nitrogen and total phosphorus were measured as nitrate and phosphate after oxidize the sample. It was based on the method proposed by Köthe and Bitsch (1992), dissolving 1.5 microspoons of Oxisolv ${ }^{\circledR}$ (Merck KGaA, Darmstadt, Germany) in $10 \mathrm{ml}$ of sample and then incubating at $100^{\circ} \mathrm{C}$ for $1 \mathrm{~h}$ to completely oxidize the phosphorus and nitrogen. The organic forms of nitrogen and phosphorus were calculated as the difference between total nitrogen or phosphorus and the sum of the rest of species analyzed. Chemical oxygen demand (COD) was determined according to Standard Methods 5220-D (APHA, 1992).

At the end of the experiment, microalgae were harvested by centrifugation (Centrifuge Mixtasel-BL Selecta ${ }^{\circledR}$ ) at $4200 \mathrm{rpm}$ for $10 \mathrm{~min}$. The resulting pellets were rinsed twice with deionized water by resuspending and centrifuging. Algae pellets were dried in a lyophilizer (Labconco, FreeZone Triad Cascade Benchtop) and ground to powder. This powder was used for all further biomass composition analyses.

The carbon and nitrogen content of the dry biomass were measured in duplicate using an elementary analyzer (LECO CHNS-932, Leco Corporation). For total phosphorus determination an acid digestion of the dry biomass was done in triplicate in a microwave digester (ETHOS 1600, Milestone) and total phosphorus was

Table 2

Experimental matrix (experimental design).

\begin{tabular}{lcl}
\hline Reactor & $\begin{array}{l}\text { Initial biomass } \\
\text { concentration }\left(\mathrm{mg} \mathrm{SS} \mathrm{l}^{-1}\right)\end{array}$ & Illumination \\
\hline Low biomass-light & 150 & Yes \\
Low biomass-dark & 150 & No \\
High biomass-light & 1500 & Yes \\
High biomass-dark & 1500 & No \\
\hline
\end{tabular}


determined by means of inductively coupled plasma atomic emission spectroscopy (ICP-AES, Iris intrepid, Thermo Elemental).

The biomass lipid content was determined in duplicate. The lipids were extracted according to a modified method reported by Takagi et al. (2006) and Wiltshire et al. (2000). To $90 \mathrm{mg}$ of lyophilized pellets, $12 \mathrm{ml}$ of 2:1 trichloromethane:methanol mixture and $0.6 \mathrm{~g}$ of analytical grade quartz were added and the mixture was sonicated in a bath $(60 \mathrm{kHz} ; 360 \mathrm{~W})$ for $90 \mathrm{~min}$. Extraction was done twice and both extracts were mixed, centrifuged and filtered to ensure quartz separation. Filtrate was evaporated under reduced pressure in a rotary evaporator. The remainder was dried at $100-105^{\circ} \mathrm{C}$ for $12 \mathrm{~h}$ and weighed as total lipid.

\subsection{Calculations}

Nutrient removal was fitted to a first-order kinetics (Eq. (1)):

$N(t)=N S_{0} \cdot e^{-\mu_{N} \cdot t}$

$N(t)$ : Momentary concentration of nutrient $\left(\mathrm{ML}^{-3}\right)$.

$N S_{0}$ : Soluble nutrient concentration in the reactor at the beginning of the experiment $\left(\mathrm{ML}^{-3}\right)$.

$\mu_{N}$ : Specific nutrient removal rate $\left(\mathrm{T}^{-1}\right)$.

Nitrogen and phosphorus contents in the biomass can be calculated analytically (see Section 2.4 and Table 5) or indirectly by means of the data of biomass concentration, nutrient content of the inoculum and the amount of nutrient removed:

Nutrient $_{\text {biomass }}(\%)=\left(\left(\left(X_{o} \cdot Y_{o}^{-1}\right)+N S_{o}-N S_{f}\right) \cdot X_{f}^{-1}\right) \cdot 100$

Being:

$X_{0}$ : Biomass concentration at the beginning of the experiment $\left(\mathrm{ML}^{-3}\right)$.

$X_{f}$ : Biomass concentration at the end of the experiment $\left(\mathrm{M} \mathrm{L}^{-3}\right)$.

$Y_{0}$ : Yield factor for cells on substrate of the inoculum, coefficient which indicates the content of nutrients of the biomass $\left(\mathrm{M} \mathrm{M}^{-1}\right)$.

$N S_{f}$ : Soluble nutrient concentration in the reactor at the end of the experiment $\left(\mathrm{ML}^{-3}\right)$.

\section{Results and discussion}

\subsection{Biomass growth}

Biomass increased in the illuminated reactors, rising from 150 to $470 \mathrm{mg} \mathrm{SS}^{-1}$ within $48 \mathrm{~h}$ and from 1500 to $1620 \mathrm{mg} \mathrm{SS}^{-1}$ within $24 \mathrm{~h}$ in the low and high biomass reactors respectively. On the other hand, there was no significant biomass growth observed in the reactors in darkness during the study. The final biomass concentrations measured were $1480 \mathrm{mgSSl}^{-1}$ for the high biomass and $155 \mathrm{mgSSl}^{-1}$ for the low biomass. This absence of growth shows the absence of heterotrophic activity in the culture. The treated wastewater showed a COD of $60 \mathrm{mg}$ oxygen $\mathrm{l}^{-1}$, being mainly non-biodegradable organic matter as it had been submitted to a treatment with activated sludge.

No severe microbiological contamination was observed in reactors due to the short experimental time. The culture was maintained monospecific despite wastewater was not submitted to further treatment of sterilization once it was taken from the WWTP. So it can be stated that biological activity (growth and nutrient removal) in all the reactors was performed by S. obliquus.

\subsection{Nutrient removal}

Total nitrogen and phosphorus variation with time is depicted in Fig. 1. Removal of these nutrients was almost complete in all the reactors excepting that one containing microalgae in darkness at a low cellular concentration.
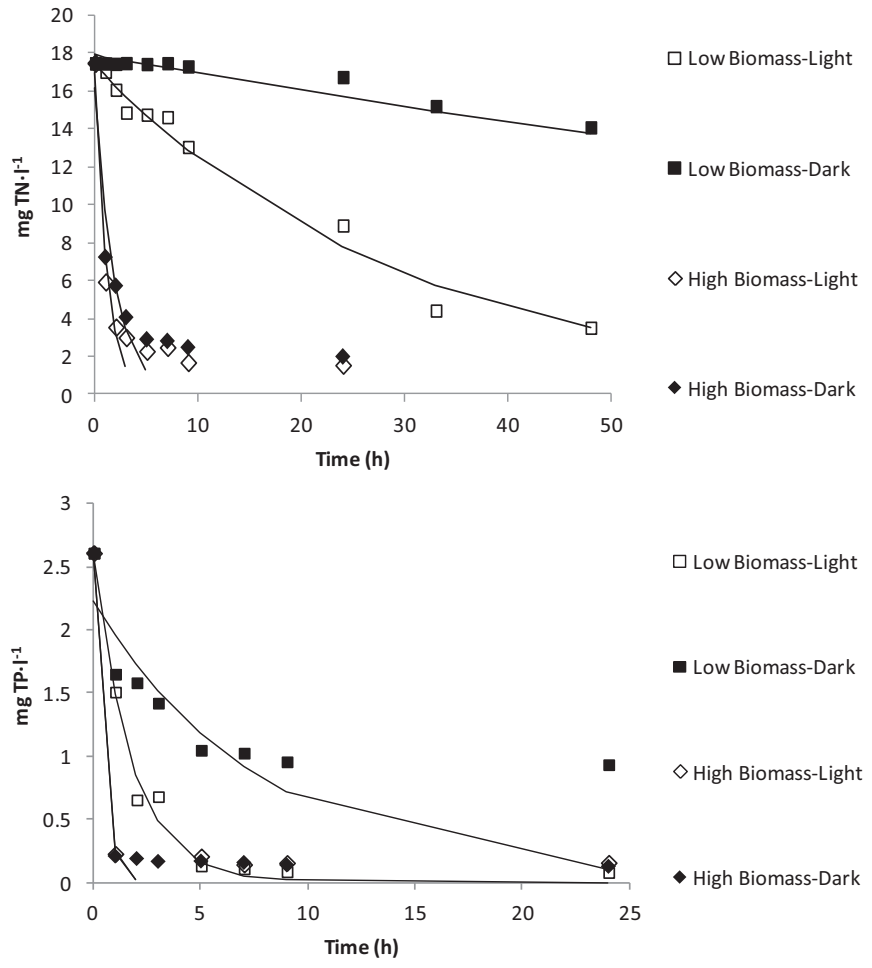

Fig. 1. Nitrogen and phosphorus removal. Symbols are experimental data and lines are the predicted data according to Eq. (1).

Fig. 1 shows that reactors with a higher initial biomass presented a high rate of nutrient removal regardless the presence of light This result agreed with those reported by (Tam and Wong, 1989), who stated that higher inoculum sizes removed more nitrogen and phosphorus from wastewater. Also Lavoie and de la Noüe (1985) reported rates of nitrogen removal proportional to biomass concentration. When light is considered, nutrient removal rate was not increased significantly by light unless a low biomass was present in the reactor. According to the results obtained, the lower microalgae concentration in darkness could not remove the nutrients from a typical wastewater effluent. Therefore, biomass concentration seemed to be more important than presence of light when considering the nutrient removal in a short period of time.

During darkness there was no significant growth of the cultures, however nitrogen assimilation (and hence uptake) continued as long as sufficient surplus of carbon was remained (Flynn and Fasham, 1997). Regarding phosphate removal rate, it was also dependent on the internal total phosphorus concentration (Rhee, 1973). Therefore, on the removal it was essential the amount of nutrients per biomass. Apparently a maximum amount of nutrients could be stored per biomass unity (Nutrient:Carbon $\max$ ) and unless carbon increased (i.e. microalgae growth), extra nutrients could not be removed. So when light was available cells could divide, biomass increased and new reserves could be accumulated (Nutrient:Carbon $<$ Nutrient:(arbon $\left.n_{\max }\right)$, and therefore nutrient removal rose.

As long as Nutrient:Carbon $\max _{\text {in }}$ in biomass was not reached, microalgae continued removing nutrients from the medium. Thereby when a high biomass concentration was present, there was much more biomass per nutrient in the wastewater (low Nutrient:Carbon in biomass) and cells did not reach the mentioned limit of nutrients reserves (Nutrient: Carbon $_{\max }$ ), so growth was not required to remove all the nutrients.

As stated, starvation of Scenedesmus sp. enhanced nitrogen and phosphorus removal (Jansson, 1993; Urrutia et al., 1995). So the 
Table 3

Time required to reach discharge values set by European Commission Directive (1998) of $10 \mathrm{mg} \mathrm{TNl}^{-1}$ and $1 \mathrm{mg} \mathrm{TPl}^{-1}$ in wastewater.

\begin{tabular}{|c|c|c|c|c|c|}
\hline & & Low biomass-light & Low biomass-dark & High biomass-light & High biomass-dark \\
\hline Nitrogen & $t_{10}(\mathrm{~h})$ & 16.55 & 106.51 & 0.65 & 0.95 \\
\hline Phosphorus & $t_{1}(\mathrm{~h})$ & 1.71 & 6.32 & 0.40 & 0.41 \\
\hline
\end{tabular}

condition of the inoculum was also a critical factor, depending nutrient removal directly on its composition. The lower the inoculum nitrogen and phosphorus content the higher amount of those nutrients removed from the culture media and the faster removal rate of nitrogen and phosphorus.

In this work, nutrient removal fitted first-order kinetics (Eq. (1)), being the variance explained in all the regressions higher than 0.9. Predicted data according to the model (Eq. (1)) are depicted in Fig. 1 as solid lines. According to this equation, time to reach $10 \mathrm{mg} \mathrm{TNl}^{-1}\left(t_{10}\right)$ and $1 \mathrm{mg} \mathrm{TPl}^{-1}\left(t_{1}\right)$ in wastewater could be estimated (Table 3 ). Those concentrations are the most restrictive discharge requirements regulated by the European Union (European Commission Directive, 1998).

The overall removal kinetic parameters obtained in Table 3 were the result of the combination of two processes: (I) the rate of nutrient adsorption and incorporation to the cells; and (II) the rate of transformation of these nutrients into new cells (i.e. assimilation). In the second process, a light source is needed to perform the light-phase of the photosynthesis and obtaining the biochemical reducing agent $\mathrm{NADPH}_{2}$ and the high energy compound ATP, both required in the dark-phase to reduce the $\mathrm{CO}_{2}$ to new biomass. It has been recently reported (Beruto et al., 2014) an aggregation of Chlorella vulgaris triggered by the presence of a magnetic field, which could be influenced by the presence of light. That aggregation could improve the nutrient abatement from wastewater, however this phenomenon of clustered cells was not observed in the microscope in our experiments.

As can be seen in Table 3, initial biomass concentration was the key parameter in the nutrient removal rate by microalgae. In the case of high biomass concentration experiments, the removal rates were similar regardless light conditions. This means that the measured rate was mainly associated to the first process (nutrient incorporation and adsorption). On the other hand, in the experiment with low initial biomass concentration the difference between both light conditions was higher, having a greater significance the second process of nutrient uptake (assimilation of nutrients into new cells).

$t_{10}$ and $t_{1}$ (Table 3 ) were much lower than the hydraulic retention time needed to maintain a stable biomass concentration in the reactor, which was given by the specific growth rate, i.e. the fraction of increase in biomass over a unit of time. At steady state in a continuous culture, the specific growth rate equals the dilution rate, being the average specific growth rate for freshwater microalgae $20 \mathrm{~h}^{-1}$ (Griffiths and Harrison, 2009) and the required hydraulic retention time should not be shorter than the inverse of this value (Ruiz et al., 2013a,b). Consequently, unless new microalgae were added to the wastewater, hydraulic retention time is determined by specific growth rate, otherwise biomass would be washed out.

\subsection{Biomass composition}

Table 5 shows elemental composition of the biomass at the end of the experiment. It can be observed the highest nitrogen and phosphorus content in microalgae cultured in darkness at a low biomass concentration. The reason is that a considerable amount of nutrients was removed and biomass did not increase in these reactors as light was not available. There was a luxury uptake (it is the ability to store excess nitrogen and phosphorus) and nutrients were stored as reserve compounds.

Previous studies have also reported that low light intensity has a positive effect on phosphorus content of the biomass (Hessen et al., 2002; Martínez Sancho et al., 1999; Powell et al., 2008) and has been interpreted as a fall in ATP accumulation when sufficient light energy is available. Also high light caused reductions in Nitrogen:Carbon ratios, indicating lower nitrogen content with high light (Hessen et al., 2002).

Nutrient content of cells in dark at a low biomass concentration (Table 5) seems to be the maximum nitrogen (8.04\%) and phosphorus (2.33\%) content that cell can store (Nutrient:Carbon max $_{\text {max }}$, needing further growth and consequently light to remove more nutrients from the medium. These nitrogen and phosphorus contents were similar to maximum contents reported by other authors in different species (Table 4).

Carbon content was quite stable regardless the culture conditions $(47.10 \pm 1.79 \%)$, however nitrogen and phosphorus contents were more variable with culture conditions $(6.31 \pm 1.20 \%$ and $1.08 \pm 0.71 \%$ respectively) (Table 5 ).

Values of nutrient content of biomass obtained by Eq. (2) are presented in Table 5 . It can be seen that they were similar to those determined analytically, indicating the insignificant effect of physical processes of nutrient removal (phosphate precipitation or ammonia stripping) during the experiment as all the nutrients removed were present in the biomass.

Lipid content was stable during the experiment, around $15.03 \pm 0.51 \%$ of the dry biomass (Table 5 ). Differences in lipid content between reactors at the beginning and the end of the tests were not significant. Therefore it can be concluded that in so short time, lipid accumulation in these culture conditions was no noticeable.

\subsection{Application of the results to wastewater treatment}

Nutrient removal depends on the microalgae concentration and inoculum nutrient content. Light also will be an influencing factor in the case that Nutrient:Carbon in biomass was close to

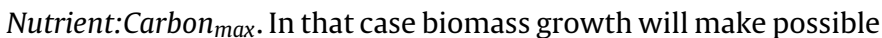
a further nutrient removal. A non-illuminated reactor specifically designed to remove nutrients operating in batch would be more advantageous than illuminated systems as the ratio surface:volume could be greatly diminished.

Table 4

Maximum nitrogen and phosphorus content in biomass reported by different authors.

\begin{tabular}{|c|c|c|c|}
\hline Species & $\% \mathrm{~N}$ & $\% \mathrm{P}$ & Authors \\
\hline Consortium & 9.27 & 0.87 & Chinnasamy et al. (2010) \\
\hline S. obliquus & - & 0.99 & Martínez et al. (2000) \\
\hline Nannochloropsis oculta & 8.3 & - & Hsueh et al. (2009) \\
\hline Chlorella sorokiniana & 10.1 & - & Richardson et al. (1969) \\
\hline Consortium (Scenedesmus sp. dominant) & - & 3.16 & Powell et al. (2008) \\
\hline Scenedesmus sp. & - & 3.5 & Yin-Hu et al. (2012) \\
\hline
\end{tabular}


Table 5

Biomass composition at the beginning (inoculum) and at the end of the tests ( 48 and $24 \mathrm{~h}$ for low and high biomass concentration respectively).

\begin{tabular}{|c|c|c|c|c|c|c|c|}
\hline & $\% \mathrm{C}$ & $\% \mathrm{~N}_{\text {meas }}{ }^{*}$ & $\% \mathrm{~N}_{\text {calcul }}{ }^{* *}$ & $\% \mathrm{P}_{\text {meas }}{ }^{*}$ & $\% \mathrm{P}_{\text {calcul }}{ }^{* *}$ & \%Others & \%Lipids \\
\hline Inoculum & $49.63 \pm 0.15$ & $5.93 \pm 0.04$ & - & $0.67 \pm 0.01$ & - & 43.77 & $15.45 \pm 0.61$ \\
\hline Low biomass-light & $46.25 \pm 0.15$ & $4.85 \pm 0.07$ & 4.86 & $0.68 \pm 0.03$ & 0.75 & 48.22 & $14.9 \pm 0.33$ \\
\hline Low biomass-dark & $47.71 \pm 0.25$ & $8.04 \pm 0.01$ & 10.72 & $2.33 \pm 0.03$ & 1.56 & 41.92 & $14.86 \pm 0.5$ \\
\hline High biomass-light & $44.80 \pm 0.12$ & $5.89 \pm 0.03$ & 5.97 & $0.78 \pm 0.01$ & 0.70 & 48.53 & $15.59 \pm 0.86$ \\
\hline High biomass-dark & $47.10 \pm 0.10$ & $6.86 \pm 0.03$ & 7.02 & $0.92 \pm 0.05$ & 0.83 & 45.12 & $14.33 \pm 0.22$ \\
\hline
\end{tabular}

* Value determined analytically.

** Value calculated by means of the Eq. (2).

From the results of this work, it is deduced that to remove nitrogen and phosphorus, high biomass concentrations are much more efficient, leading to a shorter hydraulic retention time and reactor volume. A reactor specifically designed to remove nutrients from wastewater with a high biomass concentration presents a slightly faster kinetic when it is irradiated (Table 3). However it is not so clear it was more convenient an illuminated reactor than a reactor in darkness since design must be different.

According to the results obtained, nitrogen sets the retention time to operate the reactor, as its removal below the discharge limits to comply with the Directive 98/15/EC (European Commission Directive, 1998) takes longer than for phosphorus (Table 3). Considering the mentioned retention times and a flow to be treated of $5000 \mathrm{~m}^{3} \mathrm{~d}^{-1}$ (average flow of the WWTP source of wastewater under study), the volume of the reactor needed would be $135 \mathrm{~m}^{3}$ for an illuminated reactor and $198 \mathrm{~m}^{3}$ for a reactor in darkness. For the illuminated reactor, a tubular photobioreactor can be used as model since biomass concentration in this kind of reactors is $\sim 1.3 \mathrm{~g} \mathrm{SSl}^{-1}$, similar to the studied in this work, being the surface-to-volume $(S / V)$ ratio $14.2 \mathrm{~m}^{-1}$ (Acién et al., 2012). As a model of dark reactor, a typically biological reactor for wastewater treatment as an aerated activated sludge can be used. According to Metcalf and Eddy (1991) the relation $S / V$ for this reactor is between 0.13 and $0.22 \mathrm{~m}^{-1}$, $0.17 \mathrm{~m}^{-1}$ in average. The area covered by the system can be calculated, resulting in a dramatic reduction of land use with a reactor in darkness, i.e. $1923 \mathrm{~m}^{2}$ for the illuminated reactor and $34 \mathrm{~m}^{2}$ for the reactor in darkness.

\section{Conclusions}

S. obliquus has shown the ability to uptake nutrients in darkness, which could lead to new configurations of reactors aimed to wastewater treatment, reducing the land requirements significantly.

The removal rate of nitrogen and phosphorus was proportional to the biomass concentration and the light was not critical unless the maximum nutrient storage capacity in the biomass was reached. Indeed the nutrient removal rate was more dependent on the internal biomass nutrient content than on the light presence or biomass concentration.

The hydraulic retention times needed to remove nutrients from wastewater were much lower than those required to maintain a stable biomass concentration. Consequently, to avoid the washout of the reactor, further growth in an illuminated reactor and recirculation of microalgae biomass are needed.

\section{Acknowledgments}

The authors would like to thank the Regional Government of Andalusia (Consejería de Innovación, Ciencia y Empresa, Junta de Andalucía, Spain) the funding for this study [REF.:P08-TEP-03854].

\section{References}

Acién, F.G., Fernández, J.M., Magán, J.J., Molina, E., 2012. Production cost of a real microalgae production plant and strategies to reduce it. Biotechnol. Adv. 30 (6), 1344-1353.
American Public Health Association, APHA-AWWA-WEF, Water Environment Federation, 1992. Standard Methods for the Examination of Water and Wastewater, 18th ed. American Public Health Association, Washington DC.

Arbib, Z., Ruiz, J., Álvarez, P., Garrido, C., Barragán, J., Perales, J.A., 2013. Long term outdoor operation of a tubular airlift pilot photobioreactor and a high rate algal pond as tertiary treatment of urban wastewater. Ecol. Eng. 52 $143-153$.

Beruto, D.T., Lagazzo, A., Frumento, D., Converti, A., 2014. Kinetic model of Chlorella vulgaris growth with and without extremely low frequency-electromagnetic fields (EM-ELF). J. Biotechnol. 169, 9-14.

Boyd, C.E., Musig, Y., 1981. Orthophosphate uptake by phytoplankton and sediment. Aquaculture 22, 165-173.

Chinnasamy, S., Bhatnagar, A., Hunt, R.W., Das, K.C., 2010. Microalgae cultivation in a wastewater dominated by carpet mill effluents for biofuel applications. Bioresour. Technol. 101, 3097-3105.

European Commission Directive, C., 1998. Amending Council Directive 91/271/EEC with respect to certain requirements established in Annex I. OJEC Vol. 98/15/EC (Feb), 29-30.

Flynn, K.J., Fasham, M.J.R., 1997. A short version of the ammonium-nitrate interaction model. J. Plankton Res. 19, 1881-1897.

Flynn, K.J., Fasham, M.J.R., Hipkin, C.R., 1997. Modelling the interactions between ammonium and nitrate uptake in marine phytoplankton. Philos. Trans. R. Soc. Lond. B Biol. Sci. 352, 1625-1645.

Franchino, M., Comino, E., Bona, F., Riggio, V.A., 2013. Growth of three microalgae strains and nutrient removal from an agro-zootechnical digestate. Chemosphere 6, 738-744.

Griffiths, M., Harrison, S., 2009. Lipid productivity as a key characteristic for choosing algal species for biodiesel production. J. Appl. Phycol. 21, 493-507.

Hessen, D.O., Faerovig, P.J., Andersen, T., 2002. Light, nutrients, and P:C ratios in algae: Grazer performance related to food quality and quantity. Ecology 83 , 1886-1898.

Hodaifa, G., Martínez, M.E., Órpez, R., Sánchez, S., 2012. Inhibitory effects of industrial olive-oil mill wastewater on biomass production of Scenedesmus obliquus. Ecol. Eng. 42, 30-34.

Hsueh, H.T., Li, W.J., Chen, H.H., Chu, H., 2009. Carbon bio-fixation by photosynthesis of Thermosynechococcus sp CL-1 and Nannochloropsis oculta. J. Photochem. Photobiol. B 95, 33-39.

Jansson, M., 1993. Uptake, exchange, and excretion of orthophosphate in phosphatestarved Scenedesmus quadricauda and Pseudomonas K7. Limnol. Oceanogr. 38, $1162-1178$.

Jeyanayagami, S., 2005. True confessions of the biological nutrient removal process. Fla. Water Resour. J. (Jan), 37-56.

Kilham, S., Kreeger, D., Lynn, S., Goulden, C., Herrera, L., 1998. COMBO: a defined freshwater culture medium for algae and zooplankton. Hydrobiologia 377, 147-159.

Köthe, J., Bitsch, R., 1992. Oxisolv ${ }^{\circledR}$ plus microwave - a new way for sample pretreatment and sample preparation. Fresenius J. Anal. Chem. 343, 717-718.

Lavoie, A., de la Noüe, J., 1985. Hyperconcentrated cultures of Scenedesmus obliquus: a new approach for wastewater biological tertiary treatment? Water Res. 19, 1437-1442.

Martínez, M.E., Sánchez, S., Jiménez, J.M., El Yousfi, F., Muñoz, L., 2000. Nitrogen and phosphorus removal from urban wastewater by the microalga Scenedesmus obliquus. Bioresour. Technol. 73, 263-272.

Martínez Sancho, M., Jiménez Castillo, J.M., El Yousfi, F., 1999. Photoautotrophic consumption of phosphorus by Scenedesmus obliquus in a continuous culture. Influence of light intensity. Process Biochem. 34, 811-818.

McGinn, P.J., Dickinson, K.E., Park, K.C., Whitney, C.G., MacQuarrie, S.P., Black, F.J., Frigon, J.C., Guiot, S.R., O‘Leary, S.J.B., 2012. Assessment of the bioenergy and bioremediation potentials of the microalga Scenedesmus sp AMDD cultivated in municipal wastewater effluent in batch and continuous mode. Algal Res. 1-2. 155-165.

Maurer, M., Schwegler, P., Larsen, T.A., 2003. Nutrients in urine: energetic aspects of removal and recovery. Water Sci. Technol. 48, 37-46.

Metcalf, L., Eddy, H.P., 1991. Wastewater Engineering: Treatment, Disposal and Reuse, 3rd ed. McGraw-Hill, New York.

Park, J., Jin, H.-F., Lim, B.-R., Park, K.-Y., Lee, K., 2010. Ammonia removal from anaerobic digestion effluent of livestock waste using green alga Scenedesmus sp. Bioresour. Technol. 101, 8649-8657.

Portielje, R., Lijklema, L., 1994. Kinetics of luxury uptake of phosphate by algaedominated benthic communities. Hydrobiologia 275-276, 349-358.

Powell, N., Shilton, A.N., Pratt, S., Chisti, Y., 2008. Factors influencing luxury uptake of phosphorus by microalgae in waste stabilization ponds. Environ. Sci. Technol. 42, 5958-5962. 
Powell, N., Shilton, A.N., Pratt, S., Chisti, Y., Pratt, S., 2009. Towards a luxury uptake process via microalgae - defining the polyphosphate dynamics. Water Res. 43, 4207-4213.

Rhee, G.Y., 1973. A continuous culture study of phosphate uptake, growth rate and polyphosphate in Scenedesmus sp. J. Phycol. 9, 495-506.

Richardson, B., Orcutt, D.M., Schwertner, H.A., Martinez, C.L., Wickline, H.E., 1969. Effects of nitrogen limitation on the growth and composition of unicellular algae in continuous culture. Appl. Microbiol. 18, 245-250.

Richmond, A., 2004. Handbook of Microalgal Culture: Biotechnology and Applied Phycology. Blackwell Publishing, Oxford.

Ruiz, J., Álvarez, P., Arbib, Z., Garrido, C., Barragán, J., Perales, J.A., 2011. Effect of nitrogen and phosphorus concentration on their removal kinetic in treated urban wastewater by Chlorella vulgaris. Int. J. Phytoremediation 13 (9), 884-896.

Ruiz, J., Arbib, Z., Álvarez-Díaz, P., Garrido-Pérez, C., Barragán, J., Perales, J.A., 2013 Photobiotreatment model (PhBT): a kinetic model for microalgae biomass growth and nutrient removal in wastewater. Environ. Technol. 34 (5-8), 979-991.

Ruiz, J., Álvarez-Díaz, P.D., Arbib, Z., Garrido-Pérez, C., Barragán, J., Perales, J.A., 2013b. Performance of a flat panel reactor in the continuous culture of microalgae in urban wastewater: prediction from a batch experiment. Bioresour. Technol. 127. 456-463.

Sturm, B.S.M., Lamer, S.L., 2011. An energy evaluation of coupling nutrient removal from wastewater with algal biomass production. Appl. Energ. 88, 34993506.

Takagi, M., Karseno, Yoshida, T., 2006. Effect of salt concentration on intracellular accumulation of lipids and triacylglyceride in marine microalgae Dunaliella cells. J. Biosci. Bioeng. 101, 223-226.

Tam, N.F., Wong, Y.S., 1989. Wastewater nutrient removal by Chlorella pyrenoidosa and Scenedesmus sp. Environ. Pollut. 58, 19-34.

Urrutia, I., Serra, J.L., Llama, M.J., 1995. Nitrate removal from water by Scenedesmus obliquus immobilized in polymeric foams. Enzyme Microb. Technol. 17, 200-205.

Wiltshire, K.H., Boersma, M., Möller, A., Buhtz, H., 2000. Extraction of pigments and fatty acids from the green alga Scenedesmus obliquus (Chlorophyceae). Aquat. Ecol. 34, 119-126

Yin-Hu, W., Yin, Y., Xin, L., Hong-Ying, H., Zhen-Feng, S., 2012. Biomass production of a Scenedesmus sp. under phosphorous-starvation cultivation condition. Bioresour. Technol. 112, 193-198. 